\title{
Waterborne Acrylate-Based Hybrid Coatings with Enhanced Resistance Properties on Stone Surfaces
}

\author{
Francesca Sbardella ${ }^{1,2, *(1)}$, Lucilla Pronti ${ }^{3}$ (D), Maria Laura Santarelli ${ }^{1}$ (i), \\ José Marìa Asua Gonzàlez ${ }^{2}$ and Maria Paola Bracciale 1,* (D) \\ 1 Department of Chemical Engineering Materials Environment (DICMA) and Research Center in Science and \\ Technology for the Preservation of Historical-architectural Heritage (CISTeC), Sapienza University of Rome, \\ Rome 00184, Italy; marialaura.santarelli@uniroma1.it \\ 2 Department of Applied Chemistry, University of the Basque Country, Donostia-San Sebastián 20018, Spain; \\ jm.asua@ehu.es \\ 3 Department of Basic and Applied Sciences for Engineering (SBAI), Sapienza University of Rome, \\ Rome 00161, Italy; lucilla.pronti@uniroma1.it \\ * Correspondence: francesca.sbardella@uniroma1.it (F.S.); mariapaola.bracciale@uniroma1.it (M.P.B.)
}

Received: 10 July 2018; Accepted: 11 August 2018; Published: 15 August 2018

\begin{abstract}
The application of coating polymers to building materials is a simple and cheap way to preserve and protect surfaces from weathering phenomena. Due to its environmentally friendly character, waterborne coating is the most popular type of coating, and improving its performance is an important key of research. The study presents the results regarding the mechanical and photo-oxidation resistance of some water-based acrylic coatings containing $\mathrm{SiO}_{2}$ nanoparticles obtained by batch miniemulsion polymerization. Coating materials have been characterized in terms of hydrophobic/hydrophilic behavior, mechanical resistance and surface morphology by means of water-contact angle, and scrub resistance and atomic force microscopy (AFM) measurements depending on silica-nanoparticle content. Moreover, accelerated weathering tests were performed to estimate the photo-oxidation resistance of the coatings. The chemical and color changes were assessed by Fourier-transform infrared spectroscopy (FTIR) and colorimetric measurements. Furthermore, the nanofilled coatings were applied on two different calcareous lithotypes (Lecce stone and Carrara Marble). Its properties, such as capillary water absorption and color modification, before and after accelerated aging tests, were assessed. The properties acquired by the addition of silica nanoparticles in the acrylic matrix can ensure good protection against weathering of stone-based materials.
\end{abstract}

Keywords: waterborne coatings; batch miniemulsion; weathering; stone preservation

\section{Introduction}

One of the major problems of building materials exposed to the outdoors are the environmental conditions that seriously affect their durability. Among abiotic factors, water penetration is considered a major liability, particularly for porous materials. A common practice to preserve building materials from weathering is to use water-repellent surfaces [1,2] due to their ability to control the transport of different fluids between the surface and the interior, besides having other useful properties, such as antibiofouling, antisticking, anticorrosion, stain resistance, and self-cleanability [3-7]. The most effective and cheap way to provide these properties is the application of polymer-coating compositions obtained from various monomers, like acrylics, fluorinated, and silicon-based materials $[8,9]$. Particularly, acrylic and methacrylic monomers are widely used in this way for the protection of walls, façades, consolidation of monuments, and cultural heritage sites. Some important parameters of this class of materials are transparency, water repellence, and being lightweight. In addition, 
to provide high durability for façades and floors, these surface treatments must have high adhesive power and good mechanical properties (scratch and wear resistance). However, serious durability issues arise when such acrylic systems are used on structures located outdoors. Moreover, protectives based on acrylic resins exhibit a scarce adhesion to porous substrates and provide insufficient water drainage and vapor permeability from the coated surface $[1,10,11]$. The treatments applied on building materials must be "breathable" to avoid physical phenomena, such as freezing/thawing cycles and salt crystallization, causing fast deterioration of stone materials [12,13]. Indeed, the stronger the hydrophobicity of the conservation material, the larger the stress between hydrophilic/hydrophobic interfaces is, and much more likely that detaching and peeling will occur [14].

Furthermore, the emerging demand of modern society to reduce the emission of volatile organic compounds (VOC) led the interest of the scientific community to develop a new type of coatings: waterborne coatings [15] that use water as a medium to disperse a resin, thus making these coatings ecofriendly and easy to apply. These coatings are environmentally friendly, as American and European regulations require waterborne coatings to have a VOC content of less than 3.5 pounds per gallon of water. In addition, due to the reduced VOC emissions during application, waterborne coatings reduce the risk of fires, are easier to clean up (creating fewer dangerous residues), and result in reduced worker exposure to organic vapors [16]. However, this class of coatings is usually weaker in mechanical performance and water resistance compared with their solvent-borne counterparts. Moreover, although waterborne coatings are easy to apply to any type of surface, the contact angle of the film rarely exhibits hydrophobic value. The key parameters of hydrophobic surface are the low surface energy of the material and the texture of the geometrical micro- or nanostructure of the surface [17-19]. In the last two decades, the application of nanosized inorganic particles, incorporated or in situ formed inside a polymeric matrix $[10,20]$, have been largely exploited in order to compensate for weaknesses and to develop a nanometric structure that promotes the development of waterborne coatings. Inorganic nanoparticles can impart the polymeric matrix with water-repellent, mechanical, thermal, electrical, optical, or adhesive properties, as well as add new functionalities useful for tailored applications [21-25].

Among the numerous inorganic nanoparticles used in polymeric coating, nanosized silica is the most common used for the enhancement of mechanical and thermal properties, in terms of mechanical strength, modulus, and thermal stability, and also for the higher water resistance of water-based nanocomposite coatings [25-31]. However, the mechanical and thermal properties are related to the amount of added nanoparticles and to the type of polymerization process. Indeed, in some cases, the glass-transition temperature $\left(T_{\mathrm{g}}\right)$ and the elastic modulus increased with increasing silica content [32]. This behavior can be due to the reduction of polymer-chain mobility by the inclusion of rigid nanoparticles. Conversely, in other cases, high amounts of nanosilica reduced the $T_{\mathrm{g}}$ and the temperature for maximum mechanical damping. Furthermore, high amount of silica nanoparticles lead to a more brittle behavior [32-36].

Because of the intrinsic hydrophilicity of inorganic nanofillers, they can be directly incorporated into waterborne resins consisting of polymer latex and aqueous-polymer dispersion. However, when the aqueous nanocomposite resins are drying, the compatibility between the polymer chains and the inorganic nanofiller dominates the dispersion state of the nanofillers. Poor compatibility generally leads to aggregates of such nanofillers during drying [37].

Organic-inorganic polymer hybrids, based on combinations of polymers with metals, ceramics, or both, have been prepared by several synthesis methodologies $[29,38]$. Considering the wide variety in terms of properties of these two materials, a crucial point is to get a product as much homogeneous as possible. To get homogeneous systems it is important that the polymer and the inorganic components show a high compatibility, which is usually achieved by chemical interaction, for example, Van-der-Waals forces, hydrogen bridges, and coordinative or covalent bonds. Therefore, either the polymer chain provides sufficient compatibility with the often-hydrophilic inorganic species or the inorganic components are adapted to the polymer chain [39]. 
Recently, miniemulsion polymerization has turned out to be an attractive way to obtain hybrid nanocomposite particles, especially when the synthesis of more complex particles is involved (core-shell, raspberry-like, etc.) As the submicron monomer droplets become the dominant site for particle nucleation, these allow the production of nanocomposite particles [26,40].

In this work, waterborne nanostructured hybrid silica/polyacrylate coatings obtained by batch miniemulsion polymerization have been synthetized and characterized by means of atomic force microscopy (AFM), static water-contact angle and scrub-resistance measurements. Several coatings with different silica loading $(2,5$, and $10 \mathrm{wbm} \%)$ were artificially aged in order to evaluate their stability to photo-oxidative weathering. Fourier-transform infrared (ATR-FTIR) and colorimetric measurements were performed on the aged samples in order to elucidate the chemical and aesthetic changes produced by photo-oxidation. Capillary water absorption tests were also performed on two carbonatic stones treated with the different latexes in order to investigate the water-repellency capability of the synthetized coatings.

\section{Materials and Methods}

\subsection{Materials}

The $30 \mathrm{wt.} \%$ water suspension of colloidal silica with commercial name of LUDOX AS-30 (size $12 \mathrm{~nm}$; SSA $220 \mathrm{~m}^{2} \cdot \mathrm{g}^{-1}$ ) was supplied from Sigma-Aldrich (Madrid, Spain). n-butyl acrylate (nBA, Quimidroga, Barcelona, Spain), methyl methacrylate (MMA, Quimidroga), acrylamide (AM, Sigma-Aldrich), acrylic acid (AA, Sigma-Aldrich), stearylacrylate (SA, $97 \mathrm{wt} \%$, Sigma-Aldrich), alkyldiphenyloxide disulfonate (Dowfax 2A1, $45 \mathrm{wt} . \%$, Dow Chemicals, Madrid, Spain), potassium persulfate (KPS, Sigma-Aldrich), and formic acid were used without any further purification. Deionized water (Milli-Q quality, MilliPore, Madrid, Spain) was used in all polymerization recipes. Hydroquinone (Sigma-Aldrich) was used to quench the reaction samples withdrawn at representative reaction times to monitor the progress of the process.

Two carbonatic lithotypes, Lecce stone (known as "Pietra solare" by Apulia, Italy) and Carrara marble (by Tuscany, Italy), were selected as substrates. Although these stones are mainly composed of calcite, they possess different porosity: Lecce stone $-38.8 \%$, Carrara marble $-0.4 \%$. Stone samples were obtained as $5 \times 5 \times 5 \mathrm{~cm}^{3}$ cubes.

\subsection{Preparation and Application of the Latexes}

Acrylic-inorganic composite latexes were synthesized via a miniemulsion polymerization by a two-step process according to the procedure already described elsewhere [41].

Initially, the oil phase was prepared by dissolving BA, MMA, AM, and AA (47, 47, 1, and $1 \mathrm{wt.} \%)$ with a $4 \mathrm{wbm} \%$ of a costabilizer (SA) under stirring for $15 \mathrm{~min}$. At the same time, the aqueous phase is obtained mixing the anionic emulsifier (Dowfax 2A1, 1 or $2 \mathrm{wbm} \%$ ), the iniziator (KPS, $2 \mathrm{wbm} \%$ ), LUDOX AS-30 (2 or 5 or $10 \mathrm{wbm} \%$ ), and water under stirring for $15 \mathrm{~min}$. The $\mathrm{pH}$ was kept at 3.5 with formic acid. Then, the oil and the aqueous phase were brought together and mixed for $15 \mathrm{~min}$. The final dispersion was sonified for $10 \mathrm{~min}$ at $70 \%$ of amplitude. During sonication, the flask was immersed in an icewater bath to avoid overheating.

Batch miniemulsion polymerizations were carried out in a 500-mL jacketed reactor equipped with a reflux condenser, stirrer, sampling device, and nitrogen inlet. The temperature was fixed at $70{ }^{\circ} \mathrm{C}$ for $3 \mathrm{~h}$. Table 1 summarized the different formulations for each latex, to whom a name was assigned that described: the first letter of the silica used, i.e., " $L$ " is for LUDOX 30; the first number referring to the percentage of the silica added $(2,5$, or $10 \mathrm{wbm} \%)$, and the last number for the percentage of the surfactant used ( 1 or $2 \mathrm{wbm} \%$ ). Furthermore, the conversion grade, the particle size, and Polydispersity Index (PDI) were reported. The particles size and the conversion grade were measured by Dynamic Light Scattering (DLS, Zetasizer Nano Series, Malvern Instrument, Malvern, UK) and gravimetric analysis, respectively. The reported average particle size (droplet size) values represent an average 
of 3 repeated measurements. The PDI that describes the degree of "nonuniformity" of a distribution (for a perfectly uniform sample, the PDI would be 0.0 ) was also measured. After $3 \mathrm{~h}$, the polymerization was almost complete and was short-stopped by an aqueous solution of $0.1 \mathrm{wt} . \%$ of hydroquinone.

Before the application of any protective coatings, the stone specimens were washed with deionized water, dried in an oven for 7 days at $60^{\circ} \mathrm{C}\left( \pm 5^{\circ} \mathrm{C}\right)$, then stored in a dry atmosphere, and weighed until constant mass $( \pm 0.1 \%)$ was reached according to UNI 10921:2001 [42].

The different latex dispersions were applied by brushing directly on the apical surface of the samples until apparent refusal (i.e., when the stone surface remained wet for $1 \mathrm{~min}$ ) [43]. Three samples for each stone and for each treatment were prepared. After each treatment, the samples were weighed and then kept at $23^{\circ} \mathrm{C}\left( \pm 5^{\circ} \mathrm{C}\right)$ until constant weight.

\subsection{Characterization}

Thin polyacrylate/silica hybrid films $(\approx 13 \mu \mathrm{m})$ were applied on glass substrates with a film applicator (Octoplex film applicator, TQC B.V., Seregno, Italy) in order to have a homogeneous surface. The films were dried overnight at $23{ }^{\circ} \mathrm{C}$ and $55 \%$ relative humidity. On these samples, hydrophobicity and resistance to wet abrasion measurements were performed. Static water-contact angle measurements were carried out according to the standard sessile-drop method by using a Data Physics OCA 20-model goniometer (DataPhysics Instruments GmbH, Filderstadt, Germany). 5- $\mu \mathrm{L}$ deionized water was placed on the films and an average of minimum 10 measurements taken from different positions on the surface were done. Scrub-resistance tests were performed according to the ASTM standard [44]. AFM was also used to analyze the morphology of the films cast on glass substrates. A commercial AFM setup (Solver, NT-MDT, Moscow, Russia) equipped with standard silicon tips (NSC16, Mikromasch, Wetzlar, Germany) was used to collect micrographs of the sample surfaces in tapping mode in air and at room conditions. The root mean square roughness $\left(R_{\mathrm{q}}\right)$ was calculated on $19 \times 19 \mu \mathrm{m}^{2}$ areas. An average of minimum 3 measurements taken from different locations on the surface were done.

Furthermore, accelerated aging tests by UV irradiation were carried out in accordance with the ISO 16474-3:2013 standard [45] on films and on coated stone samples. The climatic test chamber (Angelantoni Industrie S.r.l., Massa Martana, Italy) was equipped with medium-pressure ultraviolet lamps of mercury; these lamps emit in the full spectrum of ultraviolet (UVA, UVB, and UVC) with maximum emission peak in the UVA range at $366 \mathrm{~nm}$. The total radiation that reached all the samples was $5.2 \mathrm{~W} \cdot \mathrm{m}^{-2}$ as measured by means of radiometer. The total exposure consisted of 62 cycles and parameters of 1 cycle were as follows: $45 \mathrm{~min}$ UV radiation on and dry, $45 \mathrm{~min}$ UV off and water spraying, $55 \mathrm{~min}$ UV on and dry, and $15 \mathrm{~min}$ UV off and water spraying. The total duration of the experiment simulated a normal natural aging of 130 days, with maximum solar exposure, taking Europe as reference for the calculations. After each cycle, the samples were rotated horizontally in order to avoid concentration of radiation in one place.

Colorimetric measurements were performed on film samples to verify color modification due to light exposition. The 3 chromatic CIELab coordinates were calculated starting from diffuse-reflectance spectra acquired in the UV-vis spectral range (300-800 nm) with an AvaSpec-2048 spectrophotometer (Avantes, Apeldoorn, The Netherlands) equipped with bifurcated fibers that collect the reflected light with a $45^{\circ} / 0^{\circ}$ geometry. A Spectralon standard (Labshere SRS-99-010, 99\% reflectance) was taken as reference for the reflectance spectra. In order to quantify the color differences, the notion of a just-noticeable difference (JND $=3$ ) in stimuli has been used [46]. Furthermore, according to the literature, $\Delta E<5$ was considered as corresponding to a not-significant variation [47]. The measurements were made before and after accelerated exposure, always on the same 8 positions on the film, with the aid of a locating mask, and the arithmetic mean was calculated. During color measurements, the Spectralon standard was placed below each film cast on glass substrates.

Infrared spectroscopy was used to explain the changes in coating films caused by UV degradation. The chemical changes were detected with a Fourier-transform infrared spectrometer (FTIR, Vertex 70, 
Bruker Optik GmbH, Ettlingen, Germany) equipped with a single-reflection Diamond ATR cell, a standard MIR source (HeNe), and a room temperature DTGS detector. The ATR-FTIR spectra were recorded with 256 scans in the mid-infrared range $\left(400-4000 \mathrm{~cm}^{-1}\right)$ at a resolution of $4 \mathrm{~cm}^{-1}$.

The water capillarity absorption experiments were performed following the UNI EN 15801:2010 [48]. The tests were carried out on 3 samples for each coating formulation, before and after accelerated aging tests. The absorption coefficient $\left(\mathrm{AC}, \mathrm{kg} / \mathrm{m}^{2} \cdot \mathrm{h}^{0.5}\right)$, and the relative capillarity index (RCI) $[43,49]$ were calculated. Furthermore, in order to test the hydrophobicity of the stone surface after each coating application, the water-contact angles were measured as reported above.

\section{Results and Discussion}

As shown in Table 1, a nearly total conversion of the monomers into polymers ( $81 \%-100 \%)$ was achieved. Furthermore, DLS measurements indicate that the particle sizes are in a range between 115 to $250 \mathrm{~nm}$; finally, a very uniform dispersion in the latexes is evident, being the PDI (i.e., the square of the ratio of the standard deviation to the mean diameter size) values very close to 0 .

Table 1. The latexes synthesized by miniemulsion polymerization with acrylates and LUDOX 30.

\begin{tabular}{|c|c|c|c|c|c|c|}
\hline Sample & $\begin{array}{l}\text { Composition } \\
\text { (wt. \%) }\end{array}$ & $\begin{array}{c}\text { LUDOX AS-30 } \\
\text { (wbm } \%)\end{array}$ & $\begin{array}{c}\text { Dowfax } 2 \mathrm{A1} 1^{3} \\
(\mathrm{wbm} \%)\end{array}$ & $\begin{array}{l}\text { Conversion } \\
\text { Grade (\%) }\end{array}$ & $D(\mathrm{~nm})$ & PDI \\
\hline $\mathrm{NoSiO}_{2}$ & - & 0 & 1 & 81.2 & 142 & 0.022 \\
\hline L2_1 & BA: 47 & & 1 & 100 & 199.7 & 0.017 \\
\hline L2_2 & MMA: 47 & 2 & 2 & 96.3 & 156.1 & 0.145 \\
\hline L5_1 & AM: 1 & & 1 & 91.2 & 212.4 & 0.123 \\
\hline L5_2 & AA: 1 & 5 & 2 & 81.5 & 115.4 & 0.029 \\
\hline L10_1 & $\mathrm{SA}^{1}: 4$ & 1 & 1 & 97 & 250 & 0.101 \\
\hline L10_2 & $\operatorname{KPS}^{1}: 2$ & 10 & 2 & 98.9 & 122.8 & 0.044 \\
\hline
\end{tabular}

${ }^{1}$ weight based on monomers (wbm $\left.\%\right) ;{ }^{2}$ colloidal silica, $30 \mathrm{wt} . \%$ water suspension; ${ }^{3}$ alkyldiphenyloxide disulfonate. The values of the conversion, particle size $(D)$, and Polydispersity Index (PDI) are referred to 180 min, i.e., the end of the polymerization process.

Surface hydrophobicity of the coatings is mandatory for protection applications due to their ability to form a protective layer able to control the transport of different fluids between the surface and the bulk interior. Essential requirements for a hydrophobic surface are a low surface energy of material and a high roughness with micro- or nanostructured surface architecture [4].

As previous studies have pointed out, a liquid either follows the surface (Wenzel scenario) [17] or it leaves air inside the texture (Cassie-Baxter) [18]. In the first case, surface roughness $r$ (the ratio between the true surface area over the apparent one) is the key factor that controls contact angle; in the second case, a liquid is sitting upon a patchwork of air and solid surface. In the latter case, the contact angle is the average between the angle on the solid and the one on the air.

Figure 1a shows that the water-contact angle on polyacrylic coating $\left(\mathrm{NoSiO}_{2}\right)$ was $55^{\circ} \pm 0.2^{\circ}$. The incorporation of $\mathrm{SiO}_{2}$ nanoparticles lead to contact-angle values generally higher than $80^{\circ}$, due to the increase in surface roughness (Figure 1b). Furthermore, the high level of hydrophobicity of the coatings with $1 \mathrm{wbm} \%$ of surfactant could be attributed to the crosslinking in the coating and limited surfactant exudation due to polymer-surfactant complex formation through adsorption of surfactant onto hydrophobic polymer segments [50]. Indeed, the enhanced wettability was recognized to result from migration of the hydrophilic segment of the surfactant to the latex film surface [50].

The dispersion grade of the silica nanoparticles within the film is another important factor affecting the hydrophobic properties of the surfaces. AFM images of $19 \mu \mathrm{m} \times 19 \mu \mathrm{m}$ performed on all the nanocomposite coatings cast on glass substrates are shown in Figure 2. In the micrographs, it is observed that all the coatings exhibit a pillarlike surface fairly rough with a better dispersion of the $\mathrm{SiO}_{2}$ nanoparticles in films with $1 \mathrm{wbm} \%$ (Figure $2 \mathrm{~b}, \mathrm{~d}, \mathrm{f}$ ) than in those with $2 \mathrm{wbm} \%$ (Figure 2c,e,g) of surfactant. However, by increasing the amount of the silica, it is likely to find more spaced agglomerated particles of silica (Figure 2f) that lead to a decrease in the air pocket between the asperities. 
The higher water-contact angles were indeed attained on samples having finer, more homogeneously spread, and high pillarlike structures [4]. The agglomeration phenomenon is pretty much evident in the latexes with $2 \mathrm{wbm} \%$ of Dowfax, where large uneven clusters of $\mathrm{SiO}_{2}$ nanoparticles have settled. The standard deviation calculated from the $R_{\mathrm{q}}$ values (Figure $1 \mathrm{~b}$ ) confirms that a better homogeneous dispersion of silica nanoparticles can be achieved in the latexes with $1 \mathrm{wbm} \%$ of surfactant.
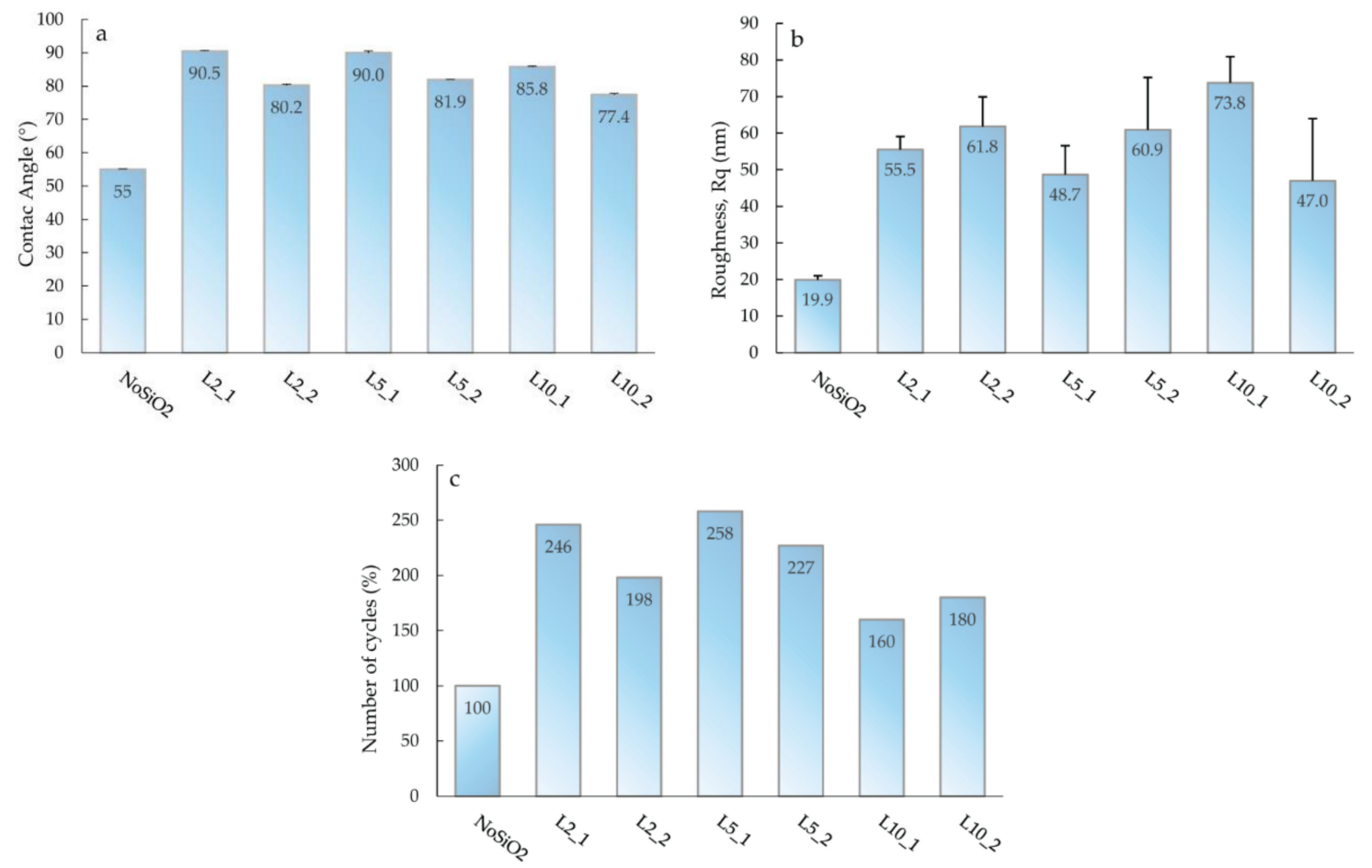

Figure 1. (a) Contact angle, (b) roughness $\left(R_{\mathrm{q}}\right)$ and (c) scrub resistance of the latex films synthesized with LUDOX 30.
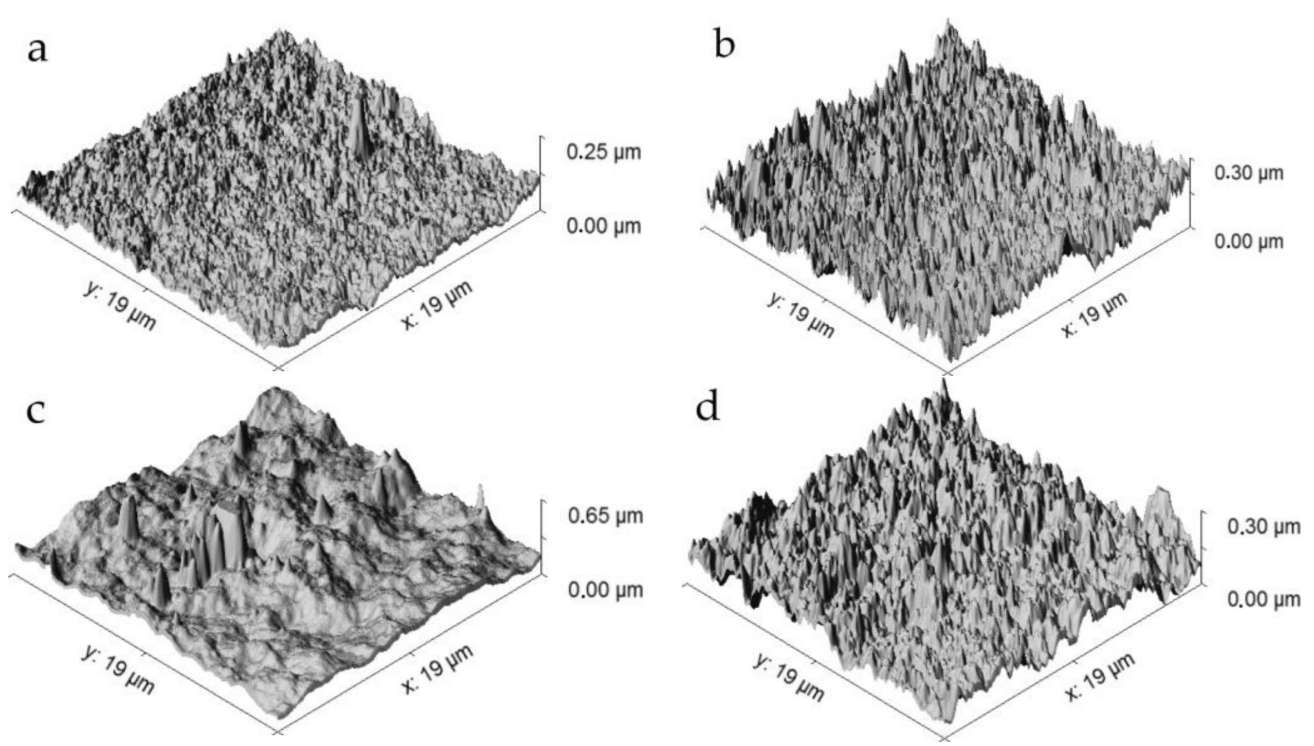

Figure 1. Cont. 

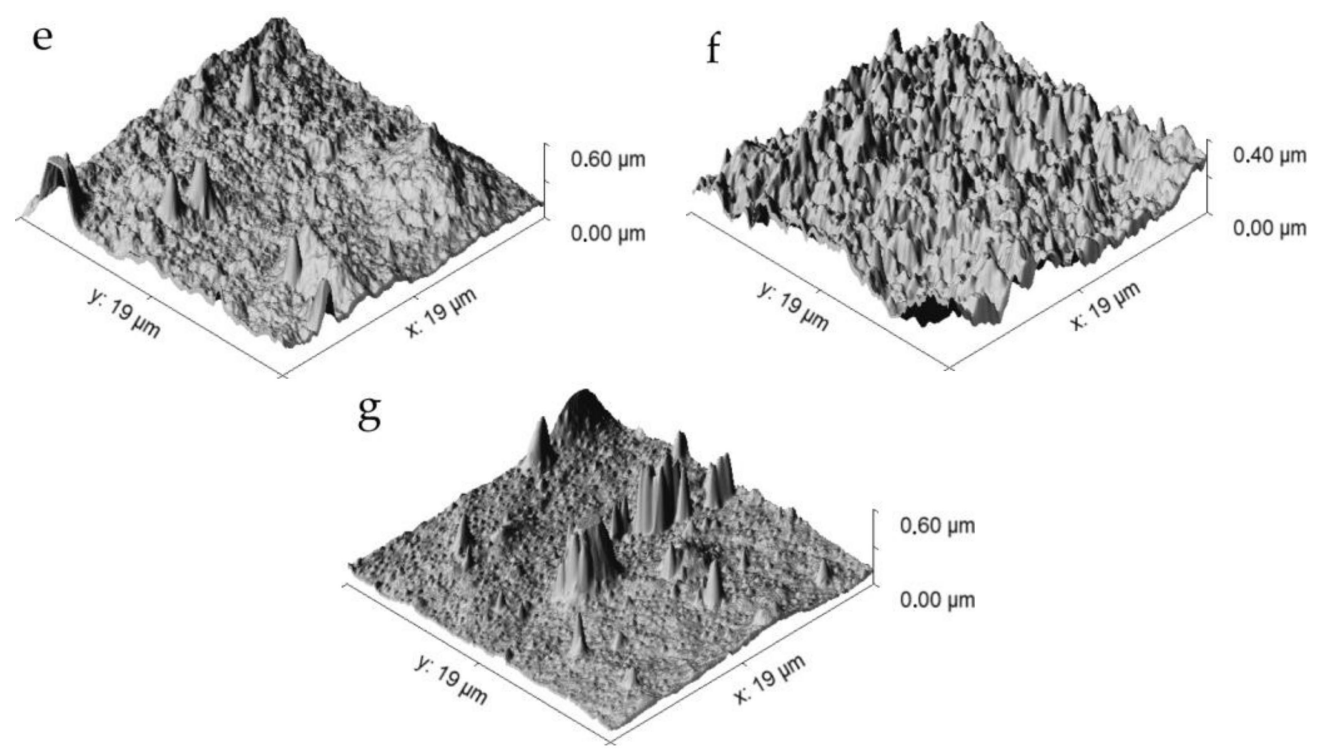

Figure 2. 3D atomic force microscopy (AFM) micrographs of hybrid coatings: (a) $\mathrm{NoSiO}_{2} ;(\mathbf{b}) \mathrm{L} 2 \_1$; (c) L2_2; (d) L5_1; (e) (L5_2); (f) L10_1; and (g) L10_2.

When the roughness data and water-contact angles were correlated, large agglomerates of the silica nanoparticles were identified leading to a hierarchical micro/nanostructure on the surface that enhances the wettability of the surfaces as previously reported [51].

In order to be applied as interior-exterior finishes, it is essential to evaluate the capability of the investigated nanocomposites not to be easily scratched and damaged. To this end, washability was evaluated by determining the resistance of the film to wet erosion by visual assessment; this parameter is also referred to as "resistance to scrubbing" or "resistance to wet abrasion" and is determined with the number of back-and-forth strokes (cycles) required to remove the film. The results show (Figure 1c) that all the latexes containing the nanosilica have an increase in resistance to wet abrasion with respect to the one without silica $\left(\mathrm{NoSiO}_{2}\right)$. Probably, the lowest scrub-resistance values of the two latexes containing $10 \mathrm{wbm} \%$ of silica (L10_1 and L10_2) are due to a nonhomogeneous dispersion of the silica into the polymer matrix.

Finally, the optimal nanoparticle content for good dispersion, enhanced hydrophobicity, and mechanical resistance was found to be $5 \mathrm{wbm} \%$.

\section{Accelerated Aging}

The chemical changes to the structure (bond scission/forming) of copolymers occurring upon $\mathrm{UV} /$ condensation-accelerated aging were monitored using FTIR-ATR and colorimetric analysis. Figure 3a shows the FTIR spectra of nonirradiated copolymer without and with $10 \mathrm{wbm} \%$ of silica. The spectrum of the neat polymer (Figure 3a, grey curve) exhibits several characteristic spectral bands, such as: $-\mathrm{OH}$ stretch $\left(3444 \mathrm{~cm}^{-1}\right), \mathrm{C}-\mathrm{H}$ stretch $\left(2956\right.$ to $\left.2874 \mathrm{~cm}^{-1}\right), \mathrm{C}=\mathrm{O}$ stretch $\left(1726 \mathrm{~cm}^{-1}\right)$, C-H bending (1386 and $\left.1450 \mathrm{~cm}^{-1}\right), \mathrm{C}-\mathrm{C}-\mathrm{O}$ stretch $\left(1267\right.$ and $\left.1236 \mathrm{~cm}^{-1}\right), \mathrm{C}-\mathrm{O}-\mathrm{C}$ stretch $(1160$ and $\left.1145 \mathrm{~cm}^{-1}\right), \mathrm{O}=\mathrm{C}-\mathrm{O}$ stretch $\left(1063 \mathrm{~cm}^{-1}\right), \mathrm{C}-\mathrm{H}$ bending in MMA $\left(989 \mathrm{~cm}^{-1}\right), \mathrm{C}-\mathrm{H}$ bending in $\mathrm{nBA}$ $\left(962 \mathrm{~cm}^{-1}\right)$, and vibrations of the side chains $\left(842\right.$ and $\left.753 \mathrm{~cm}^{-1}\right)$ [52]. After the addition of the inorganic components (Figure 3a, black curve), strong absorption bands appear at 1118 and $476 \mathrm{~cm}^{-1}$ due to Si-O-Si stretching and bending, respectively, and at $1068 \mathrm{~cm}^{-1}$ related to $\mathrm{Si}-\mathrm{O}$ bending. As shown in Figure 3b, no band shifting was observed in the UV-irradiated sample with reference to the nonirradiated sample. Particularly, the most remarkable changes detected in FTIR spectra were the increase in the absorption of the hydroxyl region, between 3400 and $3200 \mathrm{~cm}^{-1}$, due to oxidation reactions. Furthermore, relevant changes after aging are observed in the region of $1800-1600 \mathrm{~cm}^{-1}$. 
The absorption of carbonyl band $\left(1726 \mathrm{~cm}^{-1}\right)$ shows evident broadening, with the appearance of a shoulder at about 1780 and $1640 \mathrm{~cm}^{-1}$. Those effects may be attributed to a $\gamma$-lactone [43,53-55] and to terminal $\mathrm{C}=\mathrm{C}$ double bonds, respectively, produced by chain scission increasing the terminal carbon-carbon unsaturations during aging $[53,54]$.
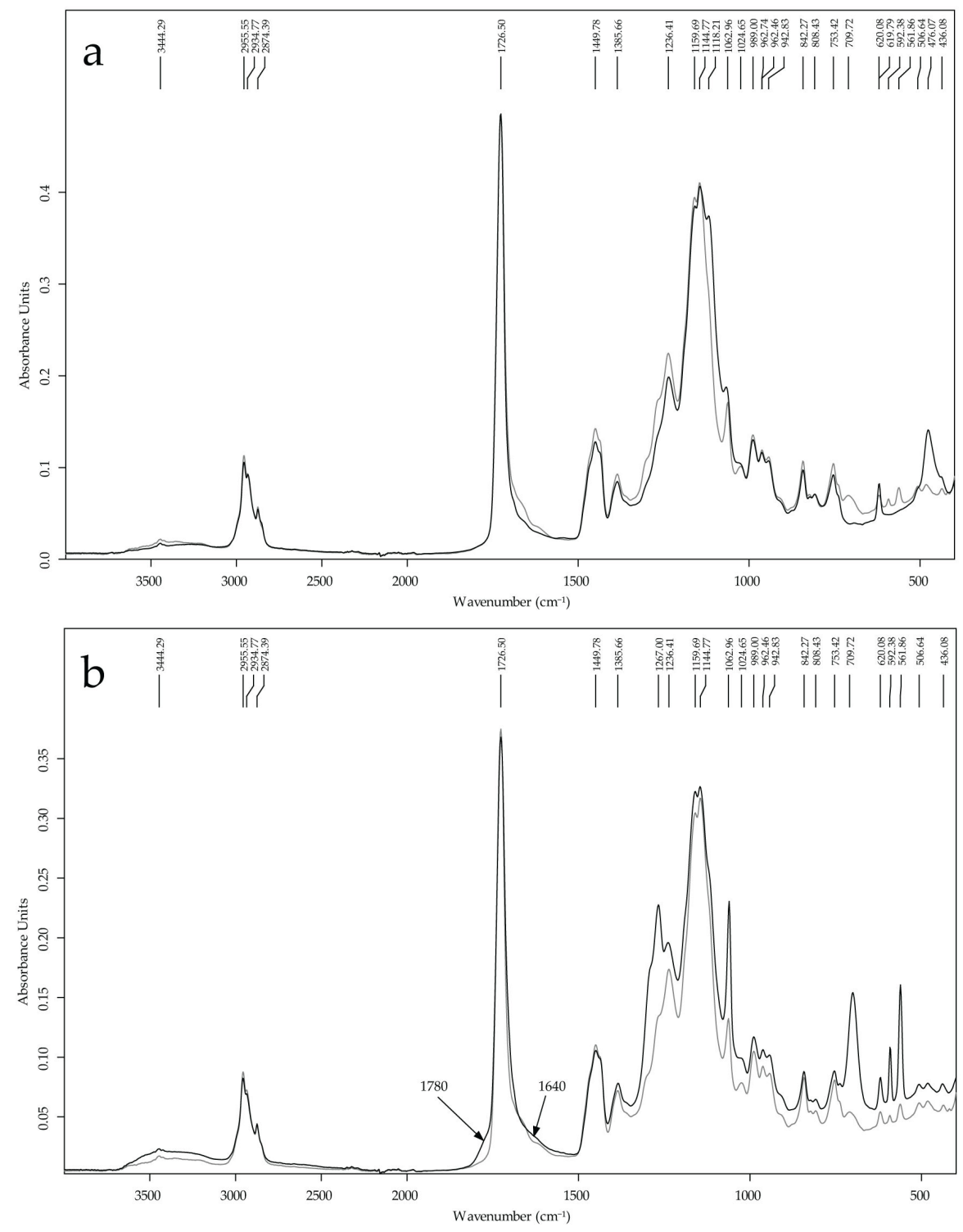

Figure 3. (a) Fourier-transform infrared spectroscopy (ATR-FTIR) spectra of latex films without (grey) and with $10 \mathrm{wt}$.\% (black) of nanosilica before UV exposure; (b) ATR-FTIR spectra of the neat films without $\mathrm{SiO}_{2}$ before (grey) after (black) UV exposure.

Furthermore, minor changes in band intensities were observed, evidencing chemical changes in the copolymer upon UV irradiation. The band underwent prominent changes is the carbonyl $(\mathrm{C}=\mathrm{O})$ stretching, which variation, as previously reported [52], was quantified after UV exposure. Indeed, considering the decrease of this band, the relative amount of the remaining functional group was determined by the ratio of IR absorbance at $1726 \mathrm{~cm}^{-1}$ after aging and the absorbance of the unexposed sample (Figure 4a) [55]. 

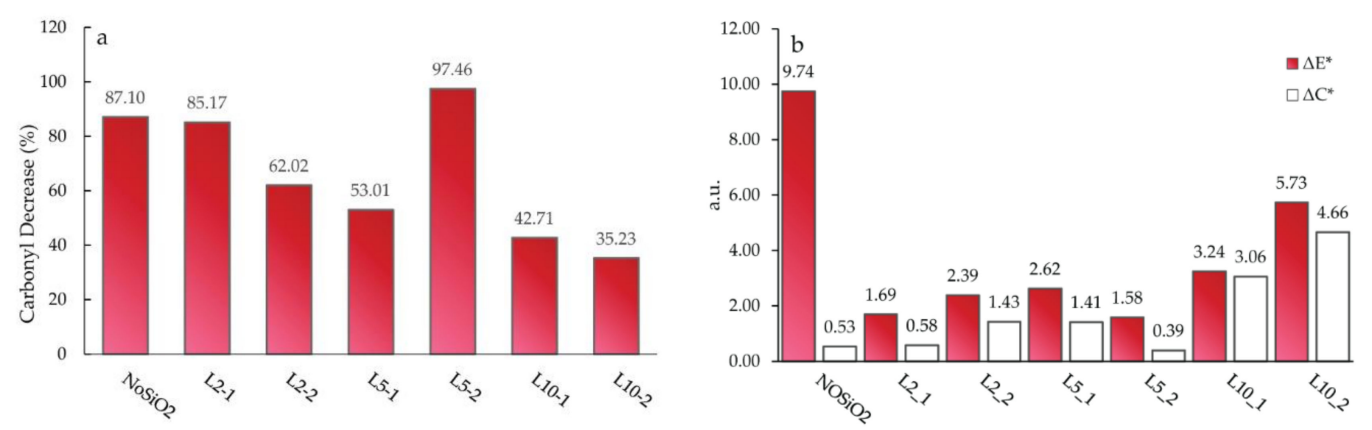

Figure 4. (a) Carbonyl decrease and (b) CIELaB determinations of the UV irradiated latexes.

The addition of nanoparticles changed the chemical structure of acrylic coatings modifying their resistances to UV-aging conditions. Figure 4a shows the calculation of the IR intensity changes of the $\mathrm{C}=\mathrm{O}$ functional group for all the coatings analyzed. The presence of $5 \mathrm{wbm} \%$ of $\mathrm{SiO}_{2}$ nanoparticles slowed the degradation of acrylic coating, as evidenced by the less-pronounced decrease of the carbonyl band in comparison with the neat coating. A higher content of inorganic nanoparticles is detrimental to the chemical stability of the films, probably due to the formation of large aggregates that inhibit the formation of a continuous cross-linked film. Furthermore, a general tendency in the photo-oxidation can be seen in coatings with $2 \mathrm{wbm} \%$ of surfactant. This phenomenon might be due to exudation and degradation of surfactant to the surface under light aging that produce hydrophilic and oxidized small molecules, which could promote radical and photochemical-degradation processes on the film surface, as previously reported [56]. The weathering of the polymers was also assessed by colorimetric changes in the total color differences $\left(\Delta E^{*}\right)$ and in the metric chroma-color difference $\left(\Delta C^{*}\right)$ using the following equations:

$$
\begin{gathered}
\Delta E^{*}=\sqrt{\left(\Delta L^{*}\right)^{2}+\left(\Delta a^{*}\right)^{2}+\left(\Delta b^{*}\right)^{2}} \\
\Delta C^{*}=\sqrt{\left(\Delta a^{*}\right)^{2}+\left(\Delta b^{*}\right)^{2}}
\end{gathered}
$$

where $L^{*}, a^{*}$, and $b^{*}$ are the brightness, the red-green component, and the yellow-blue component, respectively [46]. The total color change parameter is important for aesthetic reasons, since a coating should not induce $\Delta E^{*}$ greater than 3 [46,47], in order to preserve the original color of surfaces. The $\Delta E^{*}$ and $\Delta C^{*}$ values after aging are reported in Figure $4 \mathrm{~b}$. The neat polymer, being subjected to depolymerization after photolytic scission of main chains, shows the largest photodegradation [43]. Indeed, the highest $\Delta E^{*}$ value due to an increase in the $L^{*}$ coordinate up to the value of the Spectralon reference (Figure S1 and Table S1 in Supplementary Materials) could be a consequence of polymer loss that lead gradually to several uncoated areas [53]. No yellowing effect was detected, as proved by the negligible $C$ variation. The addition of the inorganic nanoparticles, forming a 3D network that slows down UV photo-oxidation, is in agreement with the FTIR results: in this case, the color differences are more evident in the coatings with a larger amount of $\mathrm{SiO}_{2}$ nanoparticles $(10 \mathrm{wbm} \%)$. The latter exhibits shift towards yellow coordination with reduced lightness due to the occurrence of chain scission (Figure S1 and Table S1 in Supplementary Materials).

Another important factor to be considered is the behavior of the coatings to contrast the absorption of water. Indeed, water is one of the most important factors of deterioration in porous materials thanks to its capability to penetrate by capillary absorption. Furthermore, water is the main vehicle for the transport of gaseous pollutants that can attack the components of the matrix, and physical phenomena can be induced, such as freezing/thawing cycles and salt crystallization, causing fast deterioration of the stone materials. 
To evaluate the usefulness of the coatings in decreasing water penetration, water capillary-absorption tests were carried out [48]. The measurements were performed on treated and untreated stone before and after accelerated-aging tests, simulating the coating performance under solar irradiation, which may lead to a decrease in water resistance due to chemical modifications in the polymer films. The absorption coefficient (AC), calculated as the slope of the linear part of the absorption curve in the first hour, the relative capillary index (RCI), obtained by the ratio of the water absorbed by the treated specimen and the water absorbed by the untreated one, and the contact-angle values measured on untreated and treated stones are reported in Table 2.

Table 2. Values of the contact angles, absorption coefficient (AC), and relative capillary index (RCI) of untreated and treated Lecce stone and Carrara marble before and after aging tests.

\begin{tabular}{|c|c|c|c|c|c|c|}
\hline \multirow{2}{*}{ Stone } & \multirow{2}{*}{ Coating } & \multirow{2}{*}{ Contact Angle $^{1}$} & \multicolumn{2}{|c|}{ Before Aging } & \multicolumn{2}{|c|}{ After Aging } \\
\hline & & & $\mathrm{AC}^{2}$ & RCI & $A C^{2}$ & RCI \\
\hline \multirow{8}{*}{ Lecce stone } & Untreated & 0 & 108.5 & 1.00 & 108.5 & 1.00 \\
\hline & $\mathrm{NoSiO}_{2}$ & $71.08 \pm 1.11$ & 36.1 & 0.80 & 38.5 & 0.84 \\
\hline & L2_1 & $93.95 \pm 0.49$ & 10.90 & 0.78 & 11.96 & 0.75 \\
\hline & L2_2 & $91.25 \pm 0.67$ & 13.38 & 0.85 & 9.87 & 0.78 \\
\hline & L5_1 & $92.69 \pm 0.49$ & 12.02 & 0.83 & 16.66 & 0.82 \\
\hline & L5_2 & $90.46 \pm 0.76$ & 14.06 & 0.87 & 10.21 & 0.79 \\
\hline & L10_1 & $89.77 \pm 0.65$ & 12.57 & 0.84 & 16.67 & 0.83 \\
\hline & L10_2 & $88.93 \pm 1.32$ & 13.65 & 0.85 & 10.65 & 0.78 \\
\hline \multirow{8}{*}{ Carrara marble } & Untreated & $54.08 \pm 0.68$ & 0.23 & 1.00 & 0.23 & 1.00 \\
\hline & $\mathrm{NoSiO}_{2}$ & $76.85 \pm 0.21$ & 0.13 & 0.93 & 0.11 & 0.99 \\
\hline & L2_1 & $94.60 \pm 0.28$ & 0.08 & 0.51 & 0.10 & 0.37 \\
\hline & $\mathrm{L} 2 \_2$ & $91.16 \pm 0.45$ & 0.10 & 0.63 & 0.08 & 0.35 \\
\hline & L5_1 & $92.82 \pm 0.48$ & 0.10 & 0.94 & 0.06 & 0.55 \\
\hline & L5_2 & $92.33 \pm 0.56$ & 0.09 & 0.62 & 0.13 & 0.37 \\
\hline & L10_1 & $92.15 \pm 0.88$ & 0.10 & 0.92 & 0.07 & 0.55 \\
\hline & L10_2 & $88.28 \pm 1.21$ & 0.07 & 0.60 & 0.15 & 0.38 \\
\hline
\end{tabular}

${ }^{1}$ Degree \pm standard deviation; ${ }^{2} \mathrm{~kg} / \mathrm{m}^{2} \cdot \mathrm{h}^{0.5}$.

The hydrophobic/hydrophilic behavior of the unaged stone, treated with the synthetized latexes, was firstly evaluated through static contact angle, evidencing high superficial hydrophobicity of the stone treated with nanosilica, in respect to neat latex. The results were in accordance with the former measurements performed on films casted on glass substrates.

All the treatments with polymer-nanoparticle coating affected the capillary absorption behavior compared to the untreated stones and reduced water absorption, as shown from the AC and RCI values. In detail, from the AC values, which depict the speed of the capillary rise at low times, it is clear how the absorption of water in the presence of the latexes is halved compared to the untreated reference for the latexes at $1 \mathrm{wbm} \%$ of surfactant. According to the literature, an effective hydrophobic treatment should reduce the capillary water-AC to $0.1 \mathrm{~kg} / \mathrm{m}^{2} \cdot \mathrm{h}^{0.5}$ a value small enough to provide sufficient protection against driving rain [57]. The AC values for the Carrara marble-treated stones are lower than $0.1 \mathrm{~kg} / \mathrm{m}^{2} \cdot \mathrm{h}^{0.5}$, meaning that the treatments have generally hydrophobic behavior, reducing the absorption of water by capillary effect. This hydrophobic behavior is also evident for Lecce-stone values, where the decreasing amount of water absorbed showed sharp reduction, even if the values of AC are higher than the limit proposed (0.1). This behavior could probably be due to the different porosity values of the stones and the evidently higher amount of water absorbed by Lecce stone.

After aging, the treated samples with latex without silica $\left(\mathrm{NoSiO}_{2}\right)$ showed an increase in the $\mathrm{RCI}$ value, revealing a decrease in the hydrophobic features of the organic polymer, probably due to loss of the polymer applied, as above reported for the colorimetric measurements. All the hybrid coatings are particularly stable on both the lithotypes, showing small variations of the RCI. 


\section{Conclusions}

Hybrid waterborne coatings based on acrylate copolymer containing $\mathrm{SiO}_{2}$ nanoparticles were synthesized by batch miniemulsion polymerization. The addition of nanosilica in the polymer coating increased surface roughness by the creation of nanoscale-structured surface architecture, as confirmed by AFM micrographs. This structure allowed a substantial increase in water-contact angles, creating a surface with good hydrophilic/hydrophobic balance. Furthermore, the addition of $5 \mathrm{wbm} \%$ of nanoparticles enhanced the mechanical scrub resistance and the stability of the polymer coating to photoaging thanks to the formation of homogenous organic-inorganic cross-linked structure. The accelerated photoaging of the coated stones confirms the positive effect of the inorganic nanoparticles in reducing capillary absorption, in particular at short times, and in enhancing coating stability. Therefore, the properties acquired by the addition of silica nanoparticles in the acrylic matrix can ensure good protection against the weathering of stone-based materials.

Supplementary Materials: The following are available online at http://www.mdpi.com/2079-6412/8/8/283/s1, Figure S1: CIELaB measurements of the UV irradiated latexes, Table S1: Values of the colorimetric measurements.

Author Contributions: Conceptualization, M.L.S. and J.M.A.G.; Funding Acquisition, M.L.S.; Investigation, F.S., L.P., and M.P.B.; Methodology, F.S.; Project Administration, M.L.S. and J.M.A.G.; Resources, M.L.S. and J.M.A.G.; Validation, M.P.B.; Visualization, F.S. and M.P.B.; Writing-Original Draft, F.S. and M.P.B.; Writing-Review \& Editing, M.L.S. and J.M.A.G.

Funding: This research received no external funding.

Acknowledgments: The authors would like to thank Daniele Passeri (Department of Basic and Applied Sciences for Engineering (SBAI), Sapienza University of Rome) for help with AFM, and Maria Gabriella Santonicola (Department of Chemical Engineering Materials Environment-DICMA, Sapienza University of Rome) for her kind assistance in the contact-angle measurements on tilted plane. M.L.S. thanks Paul Smith and Walter Remo Caseri (ETH Zurich) for their personal support to the project.

Conflicts of Interest: The authors declare no conflict of interest.

\section{References}

1. Doehne, E.F.; Price, C.A. Stone Conservation: An Overview of Current Research; Getty Conservation Institute: Los Angeles, CA, USA, 2010; ISBN 1606060465.

2. Khallaf, M.K.; El-Midany, A.A.; El-Mofty, S.E. Influence of acrylic coatings on the interfacial, physical, and mechanical properties of stone-based monuments. Prog. Org. Coat. 2011, 72, 592-598. [CrossRef]

3. López, A.B.; De La Cal, J.C.; Asua, J.M. Highly Hydrophobic Coatings from Waterborne Latexes. Langmuir 2016, 32, 7459-7466. [CrossRef] [PubMed]

4. Kamegawa, T.; Irikawa, K.; Yamashita, H. Multifunctional surface designed by nanocomposite coating of polytetrafluoroethylene and $\mathrm{TiO}_{2}$ photocatalyst: Self-cleaning and superhydrophobicity. Sci. Rep. 2017, 7, 13628. [CrossRef] [PubMed]

5. Wan, H.; Song, D.; Li, X.; Zhang, D.; Gao, J.; Du, C. Failure Mechanisms of the Coating/Metal Interface in Waterborne Coatings: The Effect of Bonding. Materials 2017, 10, 397. [CrossRef] [PubMed]

6. Wang, N.; Diao, X.; Zhang, J.; Kang, P. Corrosion Resistance of Waterborne Epoxy Coatings by Incorporation of Dopamine Treated Mesoporous- $\mathrm{TiO}_{2}$ Particles. Coatings 2018, 8, 209. [CrossRef]

7. Raditoiu, V.; Raditoiu, A.; Raduly, M.; Amariutei, V.; Gifu, I.; Anastasescu, M. Photocatalytic Behavior of Water-Based Styrene-Acrylic Coatings Containing $\mathrm{TiO}_{2}$ Sensitized with Metal-Phthalocyanine Tetracarboxylic Acids. Coatings 2017, 7, 229. [CrossRef]

8. Cappelletti, G.; Fermo, P.; Camiloni, M. Smart hybrid coatings for natural stones conservation. Prog. Org. Coat. 2015, 78, 511-516. [CrossRef]

9. Calia, A.; Colangiuli, D.; Lettieri, M.; Matera, L. A deep knowledge of the behaviour of multi-component products for stone protection by an integrated analysis approach. Prog. Org. Coat. 2013, 76, 893-899. [CrossRef]

10. Esposito Corcione, C.; De Simone, N.; Santarelli, M.L.; Frigione, M. Protective properties and durability characteristics of experimental and commercial organic coatings for the preservation of porous stone. Prog. Org. Coat. 2017, 103, 193-203. [CrossRef] 
11. Pia, G.; Esposito Corcione, C.; Striani, R.; Casnedi, L.; Sanna, U. Coating's influence on water vapour permeability of porous stones typically used in cultural heritage of Mediterranean area: Experimental tests and model controlling procedure. Prog. Org. Coat. 2017, 102, 239-246. [CrossRef]

12. Tabasso, M.L. Acrylic Polymers for the Conservation of Stone: Advantages and Drawbacks. APT Bull. J. Preserv. Technol. 1995, 26, 17-21. [CrossRef]

13. Siegesmund, S.; Snethlage, R. Stone in Architecture: Properties, Durability; Springer Science \& Business Media: Berlin, Germany, 2013; ISBN 3642451551.

14. Zhang, H.; Liu, Q.; Liu, T.; Zhang, B. The preservation damage of hydrophobic polymer coating materials in conservation of stone relics. Prog. Org. Coat. 2013, 76, 1127-1134. [CrossRef]

15. Paulis, M.; Asua, J.M. Knowledge-Based Production of Waterborne Hybrid Polymer Materials. Macromol. React. Eng. 2016, 10, 8-21. [CrossRef]

16. Judeinstein, P.; Sanchez, C. Hybrid organic/inorganic materials: A land of multidisciplinarity. J. Mater. Chem. 1996, 6, 511-525. [CrossRef]

17. Wenzel, R.N. Resistance of solid surfaces to wetting by water. Ind. Eng. Chem. 1936, 28, 988-994. [CrossRef]

18. Cassie, A.B.D.; Baxter, S. Wettability of porous surfaces. Trans. Faraday Soc. 1944, 40, 546-551. [CrossRef]

19. Feng, L.; Li, S.; Li, Y.; Li, H.; Zhang, L.; Zhai, J.; Song, Y.; Liu, B.; Jiang, L.; Zhu, D. Super-hydrophobic surfaces: From natural to artificial. Adv. Mater. 2002, 14, 1857-1860. [CrossRef]

20. Gagliardi, S.; Rondino, F.; D’erme, C.; Persia, F.; Menchini, F.; Santarelli, M.L.; Paulke, B.-R.; Enayati, L. Preparation and characterization of polymeric nanocomposite films for application as protective coatings. In Proceedings of the AIP Conference Proceedings, Rome, Italy, 20-23 September 2016; Volume 1873, pp. 20007-20009.

21. Kim, E.K.; Won, J.; Do, J.; Kim, S.D.; Kang, Y.S. Effects of silica nanoparticle and GPTMS addition on TEOS-based stone consolidants. J. Cult. Herit. 2009, 10, 214-221. [CrossRef]

22. Dei, L.; Salvadori, B. Nanotechnology in cultural heritage conservation: Nanometric slaked lime saves architectonic and artistic surfaces from decay. J. Cult. Herit. 2006, 7, 110-115. [CrossRef]

23. Xu, F.; Wang, C.; Li, D.; Wang, M.; Xu, F.; Deng, X. Preparation of modified epoxy-SiO 2 hybrid materials and their application in the stone protection. Prog. Org. Coat. 2015, 81, 58-65. [CrossRef]

24. Illescas, J.F.; Mosquera, M.J. Producing Surfactant-Synthesized Nanomaterials In Situ on a Building Substrate, without Volatile Organic Compounds. ACS Appl. Mater. Interfaces 2012, 4, 4259-4269. [CrossRef] [PubMed]

25. Kugler, S.; Kowalczyk, K.; Spychaj, T. Influence of dielectric nanoparticles addition on electroconductivity and other properties of carbon nanotubes-based acrylic coatings. Prog. Org. Coat. 2016, 92, 66-72. [CrossRef]

26. Zou, H.; Wu, S.; Shen, J. Polymer/silica nanocomposites: Preparation, characterization, properties and applications. Chem. Rev. 2008, 108, 3893-3957. [CrossRef] [PubMed]

27. Ma, J.-Z.; Hu, J.; Zhang, Z.-J. Polyacrylate/silica nanocomposite materials prepared by sol-gel process. Eur. Polym. J. 2007, 43, 4169-4177. [CrossRef]

28. Chau, J.L.H.; Hsieh, C.C.; Lin, Y.M.; Li, A.K. Preparation of transparent silica-PMMA nanocomposite hard coatings. Prog. Org. Coat. 2008, 62, 436-439. [CrossRef]

29. Ribeiro, T.; Baleizão, C.; Farinha, J.P.S. Functional films from silica/polymer nanoparticles. Materials 2014, 7, 3881-3900. [CrossRef] [PubMed]

30. Zhang, K.; Zheng, L.; Zhang, X.; Chen, X.; Yang, B. Silica-PMMA core-shell and hollow nanospheres. Colloids Surf. A Physicochem. Eng. Asp. 2006, 277, 145-150. [CrossRef]

31. Bao, Y.; Ma, J.; Zhang, X.; Shi, C. Recent advances in the modification of polyacrylate latexes. J. Mater. Sci. 2015, 50, 6839-6863. [CrossRef]

32. Romo-Uribe, A.; Arcos-Casarrubias, J.A.; Hernandez-Vargas, M.L.; Reyes-Mayer, A.; Aguilar-Franco, M.; Bagdhachi, J. Acrylate hybrid nanocomposite coatings based on $\mathrm{SiO}_{2}$ nanoparticles by in-situ batch emulsion polymerization. Prog. Org. Coat. 2016, 97, 288-300. [CrossRef]

33. Mahaling, R.N.; Kumar, S.; Rath, T.; Das, C.K. Acrylic elastomer/filler nanocomposite: Effect of silica nanofiller on thermal, mechanical and interfacial adhesion. Plast. Rubber Compos. 2007, 36, 267-273. [CrossRef]

34. Bandyopadhyay, A.; Bhowmick, A.K.; De Sarkar, M. Synthesis and characterization of acrylic rubber/silica hybrid composites prepared by sol-gel technique. J. Appl. Polym. Sci. 2004, 93, 2579-2589. [CrossRef]

35. Arai, K.; Mizutani, T.; Kimura, Y.; Miyamoto, M. Unique structure and properties of inorganic-organic hybrid films prepared from acryl/silica nano-composite emulsions. Prog. Org. Coat. 2016, 93, 109-117. [CrossRef] 
36. Ramos-Fernández, J.M.; Beleña, I.; Romero-Sánchez, M.D.; Fuensanta, M.; Guillem, C.; López-Buendía, Á.M. Study of the film formation and mechanical properties of the latexes obtained by miniemulsion co-polymerization of butyl acrylate, methyl acrylate and 3-methacryloxypropyltrimethoxysilane. Prog. Org. Coat. 2012, 75, 86-91. [CrossRef]

37. Zhou, S.; Wu, L. Transparent Organic-Inorganic Nanocomposite Coatings. In Functional Polymer Coatings: Principles, Methods, and Applications; Wu, L., Baghdachi, J., Eds.; Wiley: Hoboken, NJ, USA, 2015; pp. 1-71.

38. Krasia-Christoforou, T. Organic-inorganic polymer hybrids: Synthetic strategies and applications. In Hybrid and Hierarchical Composite Materials; Springer International Publishing: Cham, Switzerland, 2015; pp. 11-63. ISBN 9783319128689.

39. Kickelbick, G. Hybrid Materials_Past, Present and Future. Hybrid Mater. 2014, 1, 39-51. [CrossRef]

40. Bourgeat-Lami, E.; Lansalot, M. Organic/Inorganic Composite Latexes: The Marriage of Emulsion Polymerization and Inorganic Chemistry. In Hybrid Latex Particles: Preparation with (Mini) Emulsion Polymerization; Van Herk, A.M., Landfester, K., Eds.; Springer: Berlin/Heidelberg, Germany, 2010; Volume 233, pp. 53-123. ISBN 978-3-642-16060-8.

41. Hamzehlou, S.; Aguirre, M.; Leiza, J.R.; Asua, J.M. Dynamics of the Particle Morphology during the Synthesis of Waterborne Polymer-Inorganic Hybrids. Macromolecules 2017, 50, 7190-7201. [CrossRef]

42. UNI 10921:2001 Cultural Heritage-Natural and Artificial Stones-Water Repellents-Application on Samples and Determination of their Properties in Laboratory; UNI: Milan, Italy, 2001.

43. Bergamonti, L.; Bondioli, F.; Alfieri, I.; Alinovi, S.; Lorenzi, A.; Predieri, G.; Lottici, P.P. Weathering resistance of $\mathrm{PMMA} / \mathrm{SiO}_{2} / \mathrm{ZrO}_{2}$ hybrid coatings for sandstone conservation. Polym. Degrad. Stab. 2018, 147, $274-283$. [CrossRef]

44. ASTM D2486-00 Standard Test Methods for Scrub Resistance of Wall Paints; ASTM International: West Conshohocken, PA, USA, 2000.

45. ISO 16474-3:2013 Paints and Varnishes-Methods of Exposure to Laboratory Light Sources—Part 3: Fluorescent UV Lamps 2013; ISO: Geneva, Switzerland, 2013.

46. Sharma, G.; Bala, R. Digital Color Imaging Handbook, 1st ed.; Sharma, G., Ed.; Electrical Engineering \& Applied Signal Processing Series; CRC Press: Boca Raton, FL, USA, 2002; ISBN 978-0-8493-0900-7.

47. Mahy, M.; Van Eycken, L.; Oosterlinck, A. Evaluation of Uniform Color Spaces Developed after the Adoption of CIELAB and CIELUV. Color Res. Appl. 1994, 19, 105-121. [CrossRef]

48. UNI EN 15801:2010 Conservation of Cultural Heritage-Test Methods-Determination of Water Absorption by Capillarity; UNI: Milan, Italy, 2010.

49. Washburn, E.W. The dynamics of capillary flow. Phys. Rev. 1921, 17, 273-283. [CrossRef]

50. Li, J.; Ecco, L.; Delmas, G.; Whitehouse, N.; Collins, P.; Deflorian, F.; Pan, J. In-Situ AFM and EIS Study of Waterborne Acrylic Latex Coatings for Corrosion Protection of Carbon Steel. J. Electrochem. Soc. 2014, 162, C55-C63. [CrossRef]

51. Vázquez-Velázquez, A.; Velasco-Soto, M.; Pérez-García, S.; Licea-Jiménez, L. Functionalization Effect on Polymer Nanocomposite Coatings Based on $\mathrm{TiO}_{2}-\mathrm{SiO}_{2}$ Nanoparticles with Superhydrophilic Properties. Nanomaterials 2018, 8, 369. [CrossRef] [PubMed]

52. Shanti, R.; Hadi, A.N.; Salim, Y.S.; Chee, S.Y.; Ramesh, S.; Ramesh, K. Degradation of ultra-high molecular weight poly(methyl methacrylate-co-butyl acrylate-co-acrylic acid) under ultra violet irradiation. RSC Adv. 2017, 7, 112-120. [CrossRef]

53. Melo, M.; Bracci, S.; Camaiti, M.; Chiantore, O.; Piacenti, F. Photodegradation of acrylic resins used in the conservation of stone. Polym. Degrad. Stab. 1999, 66, 23-30. [CrossRef]

54. Allen, N.S.; Regan, C.J.; McIntyre, R.; Johnson, B.W.; Dunk, W.A.E. The photooxidative degradation and stabilisation of water-borne acrylic coating systems. Macromol. Symp. 1997, 115, 1-26. [CrossRef]

55. Nguyen, T.V.; Nguyen Tri, P.; Nguyen, T.D.; El Aidani, R.; Trinh, V.T.; Decker, C. Accelerated degradation of water borne acrylic nanocomposites used in outdoor protective coatings. Polym. Degrad. Stab. 2016, 128, 65-76. [CrossRef] 
56. Scalarone, D.; Lazzari, M.; Castelvetro, V.; Chiantore, O. Surface monitoring of surfactant phase separation and stability in waterborne acrylic coatings. Chem. Mater. 2007, 19, 6107-6113. [CrossRef]

57. Winkler, E.M. Stone in Architecture; Springer: Berlin/Heidelberg, Germany, 1997; ISBN 978-3-662-10072-1.

(c)

(C) 2018 by the authors. Licensee MDPI, Basel, Switzerland. This article is an open access article distributed under the terms and conditions of the Creative Commons Attribution (CC BY) license (http:/ / creativecommons.org/licenses/by/4.0/). 